\title{
Effect of Inserting Azabenzenes Linkers into TPA- Based Dye Sensitizers for Use in Solar Cells: DFT and TDDFT Calculations
}

\author{
AHMED M EL-NAHAS ${ }^{1},{ }^{*}$ RAMY E FARAG ${ }^{1}$, MORAD M EL-HENDAWY $^{2}$, \\ SAFINAZ H EL-DEMERDASH ${ }^{1}$ and SHABAN Y SHABAN ${ }^{3}$ \\ ${ }^{1}$ Chemistry Department, Faculty of Science, El-Menoufia University, \\ Shebin El-Kom 32512, Egypt \\ ${ }^{2}$ Department of Chemistry, Faculty of Science, Assuit University, \\ New Valley Campus, Egypt \\ ${ }^{3}$ Department of Chemistry, Faculty of Science, Kafrelsheikh University, Egypt \\ amelnahas@hotmail.com
}

Received 17 December 2015 / Accepted 11 January 2016

\begin{abstract}
Density functional theory (DFT) and time-dependent density functional theory (TDDFT) were used to study optical and electrochemical properties of a new series of dye sensitizers for use in dye-sensitized solar cells (DSSCs). The dyes include triphenylamine (TPA) unit as an electron donor and cyanoacrylic acid moiety as an electron acceptor/anchoring groups with different $\pi$-linkers. The effect of linkers on the performance of these dyes as photo-sensitizers was investigated. The linkers are benzene and azabenzenes and their hydrocarbon parent systems. The results indicated that the highest occupied molecular orbital (HOMO) is delocalized over the TPA unit and л-linker while lowest unoccupied molecular orbital (LUMO) is localized on the electron acceptor and л-linker. The HOMO level of the investigated dyes is located below the HOMO level of the $\mathrm{I}^{-} / \mathrm{I}_{3}{ }^{-}$redox couple while the LUMO is situated above the conduction band of $\mathrm{TiO}_{2}$. The gradual insertion of nitrogen at benzene bridge decreases HOMO-LUMO energy gap. This ensures good electron injection and dye regeneration. They also introduce gradual red shift by increasing nitrogens at benzene bridge which is an indicator for enhancing photocurrent. The results suggest the possibility of design of efficient photovoltaic organic materials in DSSCs from the selected dyes.
\end{abstract}

Keywords: DSSCs, Triphenylamine (TPA), Azabenzenes, TD-DFT, $\pi$-linkers, FMO

\section{Introduction}

Since its invention ${ }^{1}$, dye-sensitized solar cells (DSSCs) have drawn considerable attention for being among the most promising renewable energy devices ${ }^{2-6}$. They boast the traditional siliconbased solar cells in cost and in some other advantages ${ }^{1-4}$. Although their photon-to-current conversion efficiency (PCE) is less than the conventional solar cells, the price/performance ratio 
may be good enough to allow them for competence as a cheap source for generating electricity. The chemical stability problem is one of the drawbacks behind the lack of their entry into commercial applications at the current time ${ }^{5}$.

The components of DSSCs (dye sensitizers, anode, cathode and electrolyte) affect the $\mathrm{PCE}^{7-13}$. The requirements for an efficient solar cell sensitizers include: (1) the dye should contains anchoring groups with strong adsorption capacity to the semiconductor surface, (2) a wide absorption range in the UV/Vis to near-IR region to collect more photons from the solar spectrum, (3) proper energy level alignment of the excited state of the dye with the conduction band edge of the semiconductor and the redox level of the electrolyte with the ground state of the dye, (4) fast charge transfer from the dye to the semiconductor, with low loss of photoelectrons and (5) electrochemical and thermal stability ${ }^{6,14,15}$.

The metal-free organic dyes with good performance in DSSC usually have a donorbridge-acceptor (DBA) structure ${ }^{11,12}$. In the DBA dyes, the $\pi$-electron delocalization from the electron donor to the electron acceptor through a linker can affect the performance of DSSC ${ }^{16}$. Therefore, the $\pi$-conjugated linker between the donor and acceptor moieties plays an important role not only in tuning and modifying the optical properties of DSSC devices under the sun light irradiation, but also in controlling the intramolecular electron transfer and electron injection from the excited dye to the conduction band of the semiconductor electrode.

Improving efficiency of dyes in the UV/Vis region requires a good conjugation across the donor and anchoring group which determines the large intramolecular charge transfer character of the electronic transition. The dye aggregation and charge recombination can lead to lower the efficiency in organic sensitizers ${ }^{17-19}$. Triphenylamine (TPA) function as electron donor and the cyanoacrylic acid moiety as electron acceptor were used widely in DSSCs ${ }^{20-44}$. TPA shows a steric hindrance that can prevent unfavorable dye aggregation at the semiconductor surface ${ }^{19}$. Appropriate DBA systems are required to design efficient metal-free sensitizers for DSSCs, whose properties can be tuned by structural modifications. TPA-based DSSCs have been extensively investigated by both experimental and theoretical investigations $\mathrm{s}^{20-44}$. The $\pi$-bridges have a significant effect compared to enhancing donor ability of TPA ${ }^{45,46}$.

Computational chemistry plays a vital role in the design and development of DSSCs. It has been reported that density functional theory (DFT) and its time-dependent (TD) extension are good tools for the treatment of electronic structures and absorption spectra of different systems ${ }^{47}$. The long-range "Coulomb attenuating method" (CAM) ${ }^{48-51}$ Becke three-parameters DFT with the correlation functional of Lee et al., (B3LYP) $)^{50-52}$ has been applied to investigate excitation energies for TPA-based dyes ${ }^{30}$.

Different groups calculated ground state geometries of the TPA-based dyes at B3LYP ${ }^{52-54}$ with double and triple zeta basis sets including diffuse and polarization functions ${ }^{20-43}$. B3LYP bond lengths do not depend on the basis set and are almost identical to the MP2/6$31 \mathrm{G}(\mathrm{d}, \mathrm{p})$ values $^{32}$.

This study aims at investigating the effect of inserting $\pi$-conjugated linkers in the organic dye sensitizers derived from TPA and cyanoacrylic. The $\pi$-conjugated linkers were benzene and azabenzenes, as shown in Figure 1.

The energy gap between the highest occupied molecular orbitals (HOMO) and the lowest unoccupied molecular orbitals (LUMO) and the relevant energy gaps $\left(\mathrm{E}_{\mathrm{g}}\right)$, the absorption spectra within near-UV to visible region, the related oscillator strength $(f)$, light harvesting energy (LHE) and free energy of injection $\left(\Delta G^{\text {inject }}\right)$ of these dyes have been calculated and compared with the available experimental data, if any. 


\section{Computational details}

The ground state geometries of the investigated dyes were optimized at the three-parameter B3LYP functional ${ }^{52-54}$ with the $3-21 \mathrm{G}(\mathrm{d})$ basis set followed by single point energy calculations in dichloromethane using polarizable continuum model $(\mathrm{PCM})^{55,56}$ and $6-31+G(d, p)$ basis set. As the B3LYP hybrid functional underestimates vertical excitation energies, especially for larger dye molecules, the TD-CAM-B3LYP/6-31+G(d,p) level has been used to calculate the excitation energies for the selected dyes ${ }^{47-51}$. The combination of TD-CAM-B3LYP with the split-valence basis sets with polarization and diffuse functions guarantees accurate absorption spectra ${ }^{27}$. The calculations have been carried out in dichloromethane to match the experimental conditions ${ }^{44}$. All calculations have been conducted with the Gaussian 09 program $^{57}$.

\section{Results and Discussion}

\section{Electronic structure}

Figure 1 displays the structures of the investigated dyes. The energies of the frontier molecular orbitals (FMO) for the selected dyes are collected in Table 1. The 2-cyano-5-(4$N, N^{\prime}$-diphenylamine) penta-2,4-dienoic acid (a) has an energy gap of $2.74 \mathrm{eV}$. Inserting benzene ring, as a $\pi$-linker, between 3-, 4- positions $(\mathbf{0 N})$ decreases the energy gap to $2.28 \mathrm{eV}$. Gradual replacement of the $\mathrm{CH}$ groups of the benzene linker with nitrogen atoms destabilizes the HOMO level and stabilizes the LUMO level, thus a remarkable decrease in the HOMO-LUMO energy gap was observed. Evidently, the presence of four nitrogen atoms in 4N significantly lowers the energy gap (ca. $1.91 \mathrm{eV}$ ) compared to one, two, or three nitrogen atoms $\left(\mathbf{1 N}, \mathbf{2 N}, \mathbf{3 N}\right.$, respectively). Therefore, the $\mathrm{E}_{\mathrm{g}}$ decreases in the following order: benzene $>$ pyridine $>$ pyrazine $>1,2,4$-triazine $>1,2,4,5$-tetrazine.

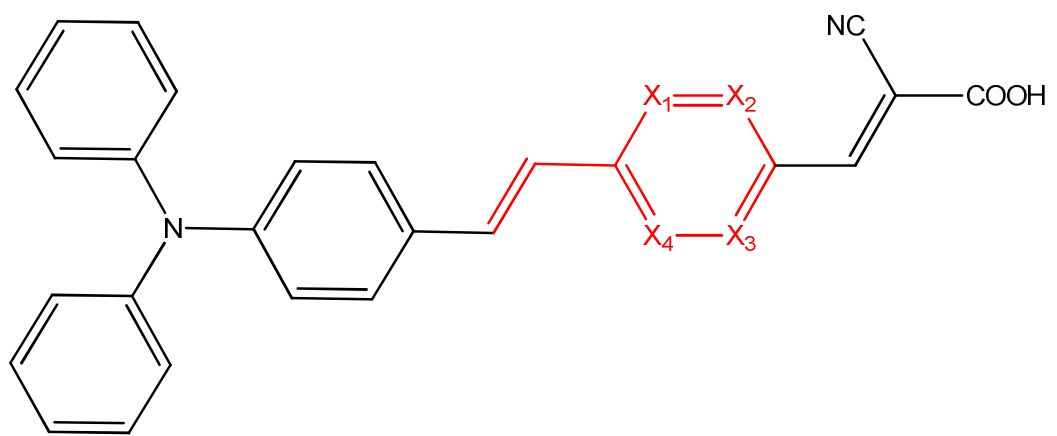

$\mathrm{N} ; 2$-Cyano-5-(4-N,N'-diphenylamine) penta-2,4-dienoic acid, $0 \mathrm{~N} ; X 1, X 2, X 3, X 4=C H, 1 N ; X 2, X 3$, $X 4=C H, X 1=N, 2 N ; X 2, X 4=C H, X 1, X 3=N, 3 N ; X 4=C H, X 1, X 2 \& X 3=N, 4 N ; X 1, X 2, X 3, X 4=N$

Figure 1. Structures of the selected triphenylamine dyes

Table 1. The HOMO, LUMO and HOMO-LUMO energies $(\mathrm{eV})$ of the selected dyes at the PCM-B3LYP/6-31+G (d,p)//B3LYP/3-21G(d) level

\begin{tabular}{cccc}
\hline Systems & $E_{\text {HOMO }}$ & $E_{\text {LUMO }}$ & $E_{\mathrm{g}}$ \\
\hline $\mathbf{0 N}$ & -5.30 & -3.02 & 2.28 \\
$\mathbf{1 N}$ & -5.36 & -3.17 & 2.19 \\
$\mathbf{2 N}$ & -5.42 & -3.35 & 2.07 \\
$\mathbf{3 N}$ & -5.48 & -3.52 & 1.96 \\
$\mathbf{4 N}$ & -5.56 & -3.65 & 1.91 \\
\hline
\end{tabular}


Good sensitizers must have narrow band gaps with their LUMOs located just above the conduction band of the semiconductor photoelectrode such as $\mathrm{TiO}_{2}$ wheretheHOMO below the HOMO of redox couple. The $\mathrm{I}^{-} / \mathrm{I}_{3}{ }^{-}$redox couple is often used as dye regenerator in DSSCs, implying that the solar cells work in solvent phase. Stabilization of LUMO of the dye ensures high photo-to-current efficiency for a given dye as a sensitizer. The HOMO and LUMO energies of bare $\left(\mathrm{TiO}_{2}\right)_{38}$ cluster are -7.23 and $-4.1 \mathrm{eV}$, respectively, resulting in an $\mathrm{E}_{\mathrm{g}}$ of 3.13 $\mathrm{eV}^{58}$. Effective electron injection is expected when the energy gap between the LUMO of the dye and the conduction band of the $\mathrm{TiO}_{2}$ is higher than $0.2 \mathrm{eV}^{59}$. An inspection of Figure 2 indicates that the LUMO energy level of $\mathbf{4 N}$ is located above the conduction band of $\mathrm{TiO}_{2}$ while the HOMO level is situated below the HOMO of the redox couple $I^{-} / I_{3}^{-}$of $-4.8 \mathrm{eV}^{59}$. This could ensure an efficient electron injection and regeneration ${ }^{60}$. Adding nitrogen atoms $(\mathbf{1 N}-\mathbf{4 N})$ stabilizes the dyes LUMO levels which could allow easy electron transfer to the semiconductor photoelectrode compared to $\mathbf{0 N}$.Previous theoretical work ${ }^{29,33,38,42}$ reported band gaps of 1.77, 2.5, 1.96 and $2.1 \mathrm{eV}$ for other di- and triphenylamine-based dyes with different $\pi$-linkers and substitutions. These values are close to those calculated for our dyes at 1.9 to $2.19 \mathrm{eV}$ and could suggest them as good sensitizers.

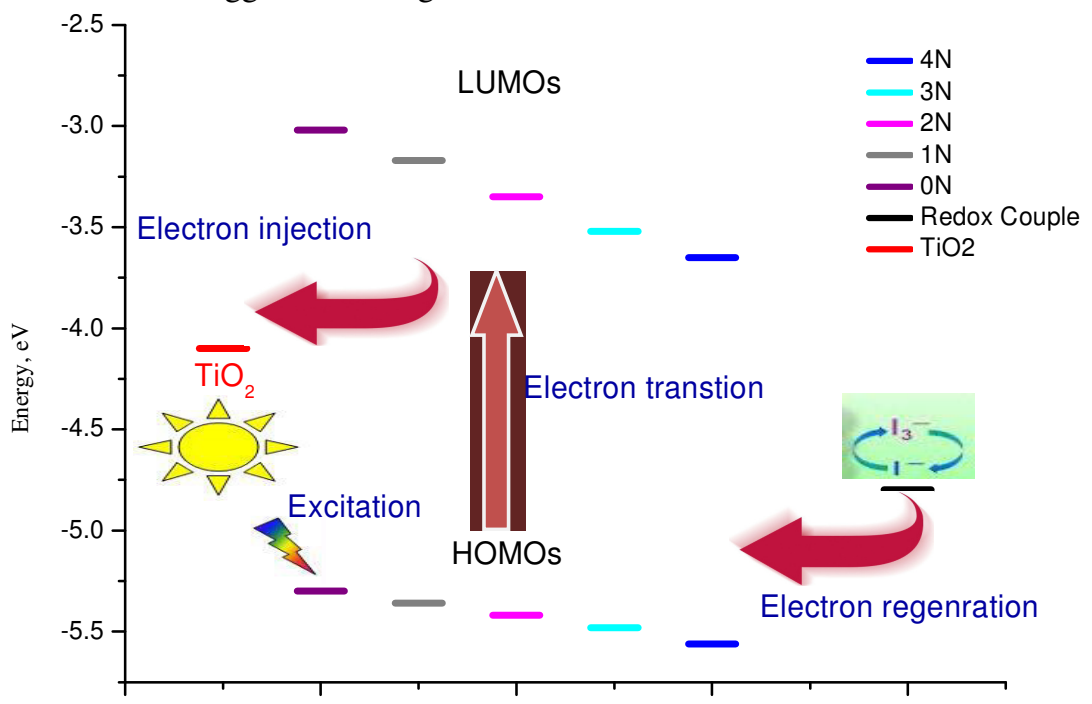

Figure 2. Sketch of PCM-B3LYP/6-31G+ (d, p)//B3LYP calculated energies of the HOMO and LUMO level of investigated compounds

The spatial distributions of HOMO and LUMO of $\mathbf{4 N}$ in the $\mathrm{S}_{0}$ state are displayed in Figure 3. The HOMO level is delocalized over TPA and $\pi$-linker while LUMO is localized on the acceptor and $\pi$-linker. This facilitates electron transfer through the dyes and guarantees good electron injection from the TPA unit to the $\mathrm{TiO}_{2}$ conduction band ${ }^{33}$.

As shown in Table 2, the projected density of state (PDOS) of all the dyes proves that the electron density is mainly located on donor and bridge moieties with a percentage (90-98\%) for the HOMOs and an excellent electron charge transfer occurs at LUMO as the electron density is distributed at bridge and acceptor moieties with a percentage (87-92\%). This is one of the features of good dyes as it's an indicator for the efficient electron transfer from HOMO to LUMO. For all dyes, TPA is a strong electron donor at HOMOs as the electron density is mainly concentrated on it and also acrylic acid is a good electron acceptor. 
Dyes

HOMO-1

$\mathbf{0 N}$

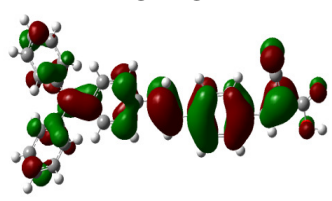

$2 \mathbf{N}$

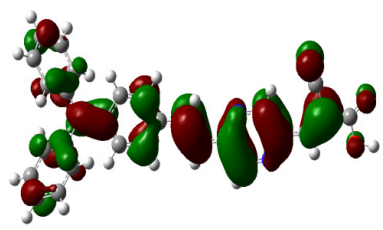

$4 \mathbf{N}$

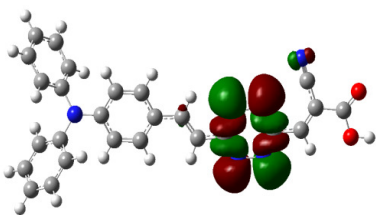

HOMO
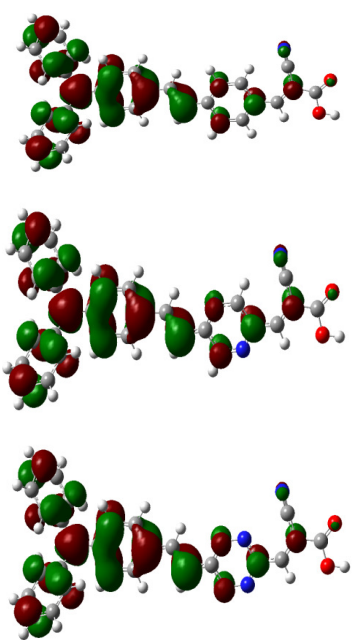

LUMO
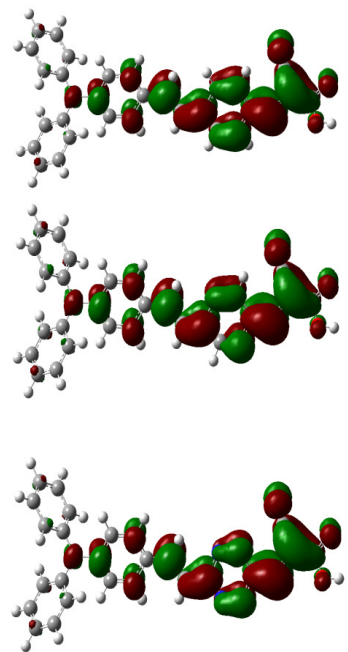

Figure 3.The HOMO-1, HOMO and LUMO spatial distribution of the designed sensitizers $\mathbf{0 N}, 2 \mathrm{~N}$ and $4 \mathbf{N}$

Table 2. Calculated projected density of state (PDOS) of the investigated dyes

\begin{tabular}{ccccccc}
\hline \multirow{2}{*}{ Systems } & \multicolumn{5}{c}{ HOMO } & \multicolumn{3}{c}{ LUMO } \\
\cline { 2 - 7 } & Donor & Bridge & Acceptor & Donor & Bridge & Acceptor \\
\hline $\mathbf{0 N}$ & 81 & 16 & 3 & 8 & 39 & 53 \\
$\mathbf{1 N}$ & 84 & 14 & 2 & 7 & 37 & 56 \\
$\mathbf{2 N}$ & 82 & 15 & 3 & 10 & 42 & 48 \\
$\mathbf{3 N}$ & 83 & 14 & 3 & 8 & 37 & 55 \\
$\mathbf{4 N}$ & 84 & 14 & 2 & 10 & 40 & 50 \\
\hline
\end{tabular}

\section{Optical properties}

The excited states in the near UV and visible regions were analyzed to determine the photophysical properties of the DBA dyes. Table 2 presents the calculated absorption spectra, oscillator strength $(f)$ and assignments of transitions for the selected dyes in dichloromethane at the PCM-TD-CAM-B3LYP/6-31+G(d,p) level of theory. The absorption spectra are displayed in Figure 4. The observed absorption band at $441 \mathrm{~nm}$ for $\mathbf{0 N}$ agrees well with the experimental value $e^{44}$ of $438 \mathrm{~nm}$. Previous calculations and experimental data of the DBA dyes in dichloromethane show two major absorption bands which were assigned to intramolecular charge transfer (ICT) and $\pi-\pi^{*}$ excitation $^{20-44}$. For the investigated dyes, the first absorption band at ca. 400-550 $\mathrm{nm}$ originates from electron transfer from the donor to the acceptor moieties, which can be considered as an ICT band. The second absorption band at ca. $280-320 \mathrm{~nm}$ is attributed to $\pi-\pi^{*}$ electron transition within the entire dyes.

Compared to $\mathbf{0 N}$, replacing $\mathrm{CH}$ of the benzene linker byone, two and three nitrogen atoms significantly affects the UV/Vis spectra and produces red shift. For instance, replacement of benzene unit with pyridine results in $13 \mathrm{~nm}$ red shift in the absorption maximum. This is because pyridine is electron deficient relative to benzene which enhances the intramolecular charge transfer from TPA to cyanoacrylic acid unit. Figure 5 shows that increasing number of nitrogen atoms in the $\pi$-linker causes more red shift of the absorption 
maxima relative to $\mathbf{0 N}$ due to rising of electron deficiency ${ }^{61}$. Interaction of the sensitizers with the photoelectrode results in an energy alignment of both the dye and semiconductor. The PCE efficiency of a given DSSC depends on its constituents, photo anode, electrolyte, absorption spectra of the dye and its contact with the semiconductor electrode. The adsorption energies of similar systems with the same anchors were calculated between 20 and $30 \mathrm{kcal} / \mathrm{mol}$ which means good contact ${ }^{10,23,26}$. The interaction between $\mathrm{TiO}_{2}$ and dye causes stabilization of the dye LUMO and destabilization of the LUMO of the $\mathrm{TiO}_{2}$ which leads to efficient electron transfer from the dye to the photelectrode conduction band ${ }^{10,23,26}$. The PCE of $\mathbf{0 N}$ was estimated ${ }^{44}$ as $9.1 \%$. Red shift is desirable for harvesting more photons. The new dyes show redshifted absorption spectra compared to $\mathbf{0 N}$ and are expected to show higher efficiency and collect more photons.

Table 3. Absorption wavelength, assignment of electronic transitions, oscillator strength, and light harvesting energy for the singlet-singlet transition in Vis and near UV regions for the selected dyes in dichloromethane at PCM-TD-CAM-B3LYP/6-31+G(d,p)

\begin{tabular}{ccccc}
\hline Systems & $\lambda_{\max }, \mathrm{nm}$ & $f$ & $\mathrm{LHE}$ & Assignment \\
\hline $\mathbf{0 N}$ & 440.7 & 1.82 & 0.9849 & $\mathrm{H} \rightarrow \mathrm{L}(61 \%), \mathrm{H}-1 \rightarrow \mathrm{L}(27 \%)$ \\
$\mathbf{1 N}$ & 453.9 & 1.72 & 0.9809 & $\mathrm{H} \rightarrow \mathrm{L}(61 \%), \mathrm{H}-1 \rightarrow \mathrm{L}(25 \%)$ \\
$\mathbf{2 N}$ & 476.5 & 1.69 & 0.9796 & $\mathrm{H} \rightarrow \mathrm{L}(62 \%), \mathrm{H}-1 \rightarrow \mathrm{L}(24 \%)$ \\
$\mathbf{3 N}$ & 477.1 & 1.50 & 0.9684 & $\mathrm{H} \rightarrow \mathrm{L}(61 \%), \mathrm{H}-1 \rightarrow \mathrm{L}(22 \%)$ \\
$\mathbf{4 N}$ & 487.9 & 1.53 & 0.9705 & $\mathrm{H} \rightarrow \mathrm{L}(63 \%), \mathrm{H}-1 \rightarrow \mathrm{L}(20 \%)$ \\
\hline
\end{tabular}

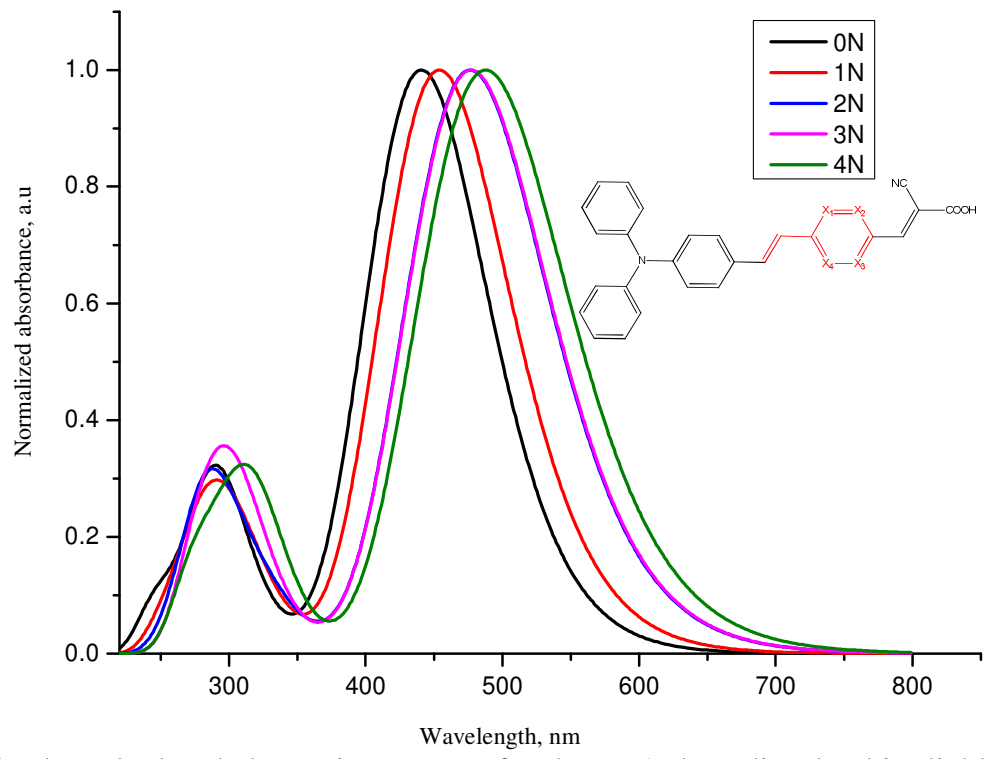

Figure 4. The calculated absorption spectra for the TPA dyes dissolved in dichloromethane at the PCM-TDCAM-B3LYP/6-31+G (d,p)//B3LYP/6-31+G(d,p) level of theory

The longest absorption wavelengths in the investigated dyes result from $S_{0}$ to $S_{1}$ electron transitions, HOMO $\rightarrow$ LUMO. The HOMO represents $\pi$-orbital which is extended over the electron-donor and linker, while the LUMO is $\pi^{*}$ that is localized on the linker of the electron-acceptor/anchoring, (Figure 4). This reveals an effective electron transition from the HOMO to LUMO and then electron transfer to the conduction band of the $\mathrm{TiO}_{2}$ electrode. 
It is known that a broad absorption covering the visible and some of the near-infrared region is favorable for good overlap with the solar spectrum to produce an enhanced photocurrent response ${ }^{34,35}$. As shown in Figures 4 the new dyes $(\mathbf{1 N}-\mathbf{4 N})$ show a red shifted absorption band from 440 to $487 \mathrm{~nm}$, which indicates an improved photo-to-current conversion compared to $\mathbf{0 N}$. Previously, absorption at 450,548 and $474 \mathrm{~nm}$ was reported ${ }^{29,33,42}$ for TPA-based dye substituted at 3, 3' positions by 2-methoxy vinyl, polyenediphenylaniline, 1,2-dimethyl vinyl groups, respectively. These values can be compared with our calculated absorption spectra which extend from 453 to $487 \mathrm{~nm}$ which cover a larger space of solar spectrum. This might ensure better performance for photon-to-current conversion once there is a good alignment between the LUMO of the dye and conduction band $(\mathrm{CB})$ of the photoelectrode. These observations indicate that the selected dyes with different $\pi$-spacers could be good candidates in the DSSC devices.

\section{Electron injection}

The light-to-electricity conversion efficiency $(\eta)$ of solar cell devices is determined from the open circuit voltage $\left(V_{O C}\right)$, short circuit current density $\left(J_{S C}\right)$, fill factor $(F F)$ and incident solar power $\left(P_{\text {inc }}\right)$ :

$$
\eta=F F \frac{V_{o c} J_{s c}}{p_{i n c}}
$$

Usually, the standard AM1.5G solar spectrum $P_{i n c}=1000 \mathrm{~W} / \mathrm{m}^{2}$ is used for solar cell efficiency calculations. The short current density $J_{S C}$ in DSSCs is determined from the following equation ${ }^{32}$ :

$$
J_{s c}=f L H E(\lambda) \Phi_{\text {inject }} \eta_{\text {collect }} d \lambda
$$

The light harvesting efficiency ( $L H E$ ) of the dye sensitizer should be as high as possibleto maximize photo-to-current conversion. LHE can be calculated from Eqn. (3) ${ }^{62}$

$$
L H F=1-10^{-f}
$$

Where $f$ is the oscillator strength of the dye associated with the $\lambda_{\max }^{I C T}$. The LHE parameter is related to light harvesting ability of the dye sensitizer and corresponds to the intramolecular charge transfer transition. The increased oscillator strength enhances the LHE value and therefore, gives rise to increase of the overlap with the solar spectrum, especially at the visible range.

Accurate $E_{C B}^{T i O_{2}}$ is difficult to be determined because of its sensitivity to the conditions e.g. the $\mathrm{pH}$ of the solution. Therefore, we used the experimental value of $-4 \mathrm{eV}$ where these miconductor is in contact with aqueous redox electrolytes at $\mathrm{pH} 7.0^{63-65}$. $\Phi_{\text {inject }}$ is related to $\Delta G^{\text {inject }}$ of electron injection from the excited states of dye molecules to the semiconductor electrode. The $\Delta G^{\text {inject }}$ is calculated as follows ${ }^{62}$ :

$$
\Delta G^{\text {inject }}=E_{o x}^{d y e^{*}} \Delta-E_{C B}^{T^{i O_{2}}}=\left(E_{o x}^{\text {dye }}-E_{0-0}^{\text {dye }}\right)-E_{C B}^{T i O_{2}}
$$

Where $E_{o x}^{d y e}$ and $E_{o x}^{d y e^{*}}$ represent the oxidation potential of the dye in the ground and excited states, respectively, $E_{C B}^{\mathrm{TiO}_{2}}$ is the conduction band edge of the semiconductor and $E_{0-0}^{d y e}$ is the 0-0 transition energy between the ground and the excited state. To estimate the 
0-0 "absorption" line, we need both the $\mathrm{S}_{0}$ (singlet ground state) and the $\mathrm{S}_{1}$ (first singlet excited state) equilibrium geometries.

As shown in Table 3, insertion of nitrogen atoms in benzene bridge $(\mathbf{1 N}-\mathbf{4 N})$, the absorption wavelengths increase. The azabenzene derivatives have reasonable values of oscillator strengths and LHE which leads to higher photo-to-current efficiency as inferred from Eqs.1-3.

Table 4 lists the injection free energies of the investigated dyes and reveals that $\Delta G^{\text {inject }}$ decrease with increasing $E_{o x}^{d y e^{*}} . \mathbf{4 N}$ has the largest $E_{o x}^{d y e^{*}}$ and its $\Delta G^{\text {inject }}$ is smaller than the corresponding values for other dyes. However, The free energy of injections is large enough to guarantee efficient electron injection. On the other hand, too large $\Delta G^{\text {inject }}$ may introduce energy redundancy, resulting asmaller $\mathrm{V}_{\text {oc }}$ and large thermalization losses ${ }^{10}$.

Table 4. Calculated electronic properties of the selected dyes $E_{o x}^{d y y^{*}}, E_{0-0}^{\text {dye }}$ and $\Delta G^{\text {inject }}$

\begin{tabular}{ccccc}
\hline Systems & $E_{\text {ox }}^{\text {dye }}$ & $E_{o x}^{\text {dye* }}$ & $E_{0-0}^{\text {dye }}$ & $\Delta G^{\text {inject }}$ \\
\hline $\mathbf{0 N}$ & 5.30 & 2.61 & 2.689 & -1.39 \\
$\mathbf{1 N}$ & 5.36 & 2.67 & 2.652 & -1.33 \\
$\mathbf{2 N}$ & 5.42 & 2.82 & 2.549 & -1.18 \\
$\mathbf{3 N}$ & 5.48 & 2.87 & 2.549 & -1.13 \\
$\mathbf{4 N}$ & 5.56 & 2.98 & 2.765 & -1.02 \\
\hline
\end{tabular}

\section{Conclusion}

The influence of $\pi$-linkers of a series of triphenylamine (TPA)-based dye sensitizers on their electronic and optical properties was studied for use in dye-sensitized solar cells (DSSCs) using DFT and TDDFT formalisms. The linker includes benzene and azabenzenes. The results indicated that the gradual insertion of nitrogen at benzene $\pi$-linker shows an enhanced spectral response (compared to $\mathbf{0 N}$ ) in the UV/Vis solar spectrum due to sharp lowering in the LUMO level and smaller HOMO-LUMO energy gap. HOMO and LUMO of the dyes are located above and below the conduction band of $\mathrm{TiO}_{2}$ photoelectrodeand the HOMO of the $\mathrm{I}^{-} / \mathrm{I}_{3}{ }^{-}$redox couple, respectively, which could guarantee efficient electron injection and regeneration assuming a good alignment of energy levels among the constituents of the solar cell. The electron transfer from the LUMO of the dyes to the conduction band of the $\mathrm{TiO}_{2}$ electrode can occur efficiently after HOMO to LUMO transition in the dye. The HOMO-LUMO energy gap decreases with increasing number of nitrogen atoms in the benzene linker. Tetrazine bridge seems more efficient as it shows a remarkable red shift in the absorption band compared to other dyes. The HOMO of the studied dyes is delocalized over the $\pi$-conjugated system with the highest electron density concentrated on the TPA moiety. On the other hand, the LUMOis localized on the anchoring group through the $\pi$-bridge. Compared to previous work, the new dyes give reasonable $\Delta G^{\text {inject }}$. This ensures better electron injection. Our simulations could suggest the new dyes as efficient sensitizers in DSSCs.

\section{References}

1. O'regan B and Grätzel M, Nature, 1991, 353, 737-740; DOI:10.1038/353737a0

2. Grätzel M, J Photochem Photobiol C: Photochem Rev., 2003, 4(1), 145-153; DOI:10.1016/S1389-5567(03)00026-1 
3. Nazeeruddin M K, Klein C, Liska P and Grätzel M, Coord Chem Rev., 2005, 249(1314), 1460-1467; DOI:10.1016/j.ccr.2005.03.025

4. Li B, Wang L, Kang B, Wang P and Qiu Y, Sol Energy Mater Sol Cells, 2006, 90(5), 549-573; DOI:10.1016/j.solmat.2005.04.039

5. Tributsch H, Coord Chem Rev., 2004, 248(13-14), 1511-1530;

DOI:10.1016/j.ccr.2004.05.030

6. Hagfeldt A, Boschloo G, Sun L, Kloo L and Pettersson H, Chem Rev., 2010, 110(11), 6595-6663; DOI:10.1021/cr900356p

7. Yahia I S, Mansour S A, Hafez H S, Ocakoglu K and Yakuphanoglu F, J Inorg Organomet Polym., 2012, 22(6), 1240-1247; DOI:10.1007/s10904-012-9723-7

8. Al-Sehemi A G, Irfan A, Asiri A M and Ammar Y A, J Mol Struct., 2012, 1019, 130134; DOI:10.1016/j.molstruc.2012.02.035

9. Shibl H M, Hafez H S, Rifai R I and Abdel Mottaleb M S A, J Inorg Organomet Polym., 2013, 23(4), 944-949; DOI:10.1007/s10904-013-9874-1

10. Feng J, Jiao Y, Ma W, Nazeeruddin Md K, Grätzel M and Meng S, J Phys Chem C, 2013, 117(8), 3772-3778; DOI:10.1021/jp310504n

11. Mishra A, Fischer M K R and Bauerle P, Angew Chem Int Ed., 2009, 48(14), 24742499; DOI:10.1002/anie.200804709

12. Zakeeruddin S M and Grätzel M, Adv Funct Mater., 2009, 19(14), 2187-2202; DOI:10.1002/adfm.200900390

13. CliffordJ N, Martinez-Ferrero E, Viterisi A and Palomares E, Chem Soc Rev., 2011, 40, 1635-1646; DOI:10.1039/B920664G

14. Grätzel M, Nature, 2001, 414, 338-344; DOI:10.1038/35104607

15. Hamann T W, Jensen R A, MartinsonA B F, VanRyswyk H and Hupp J T, Energy Environ Sci., 2008, 1, 66-78; DOI:10.1039/B809672D

16. Tai C K, Chen Y J, Chang H W, Yeh P L and Wang B C, Comput Theor Chem., 2011, 971(1-3), 42-50; DOI:10.1016/j.comptc.2011.05.036

17. Liu D, Fessenden R W, Hug G L and Kamat P V, J Phys Chem B, 1997, 101(14), 2583-2590; DOI:10.1021/jp962695p

18. Burfeindt B, Hannappel T, Storck W and Willig F, J Phys Chem., 1996, 100(41), 16463-16465; DOI:10.1021/jp9622905

19. Sayama K, Tsukagochi S, Hara K, Ohga Y, Shinpou A, Abe Y, Suga S and Arakawa H, J Phys Chem B, 2002, 106(6), 1363-1371; DOI:10.1021/jp0129380

20. Fan W, Tan D and Deng W, Phys Chem Chem Phys., 2011, 13, 16159-16167; DOI:10.1039/C1CP21308C

21. Fan W, Tan D and Deng W Q, Chem Phys Chem., 2012, 13(8), 2051-2060; DOI:10.1002/cphc.201200064

22. Ning Z, Zhang Q, Wu W, Pei H, Liu B and Tian H, J Org Chem., 2008, 73(10), 37913797; DOI:10.1021/jo800159t

23. Tarsang R, Promarak V, Sudyoadsuk T, Namuangruk S and Jungsuttiwong S, $J$ Photochem Photobiol A: Chem., 2014, 273, 8-16; DOI:10.1016/j.jphotochem.2013.09.002

24. Preat J, Michaux C, Jacquemin D and Perpéte E A, J Phys Chem C, 2009, 113(38), 16821-16833; DOI:10.1021/jp904946a

25. Yang F, Akhtaruzzaman Md, Islam A, Jin T, El-Shafei A, Qin C, Han L, Alamry K, Kosa S A, Hussein M A, Asirie A M and Yamamotoae Y, J Mater Chem., 2012, 22, 22550-22557; DOI:10.1039/C2JM34363K 
26. Li W, Wang J, Chen J, Bai F Q and Zhang H X, Spectrochimica Acta Part A: Moler Biomolec Spectro., 2014, 118, 1144-1151; DOI:10.1016/j.saa.2013.09.080

27. Abdullah M I, Janjua M, Mahmood A, Ali S and Ali M, Bull Korean Chem Soc., 2013, 34, 2093-2098.

28. Xu W, Peng B, Chen J, Liang M and Cai F, J Phys Chem C, 2008, 112(3), 874-880; DOI:10.1021/jp076992d

29. Irfan A, Mater Chem Phys., 2013, 142(1), 238-247;

DOI:10.1016/j.matchemphys.2013.07.011

30. Preat J, J Phys Chem C, 2010, 114(39), 16716-16725; DOI:10.1021/jp1050035

31. Preat J, Jacquemi D and Perpete E A, Environ Sci Technol., 2010, 44, 5666-5671; DOI:10.1021/es100920j

32. Preat J, Michaux C, Jacquemin D and Perpete E A, J Phys Chem C, 2009, 113(38), 16821-16833; DOI:10.1021/jp904946a

33. Irfan A, Jin R, Al-Sehemi A G and Asiri A M, Spectrochimica Acta Part A: Molec Biomole Spectr., 2013, 110, 60-66; DOI:10.1016/j.saa.2013.02.045

34. Preat J, Hagfeldt A and Perpète E A, Energy Environ Sci., 2011, 4, 4537-4549; DOI:10.1039/C1EE01638E

35. Fan W and Deng W, Commun Comput Chem., 2013, 1(2), 152-170; DOI:10.4208/cicc.2013.v1.n2.6

36. Justin Thomas K R, Hsu Y C, Lin J T, Lee K M, Ho K C, Lai C H, Cheng Y M and Chou P T, Chem Mater., 2008, 20(5), 1830-1840; DOI:10.1021/cm702631r

37. Li G, Jiang K J, Li Y F, Li S L and Yang L M, J Phys Chem C, 2008, 112(30), 11591-11599; DOI:10.1021/jp802436v

38. Velusamy M, Justin Thomas K R, Lin J T, Hsu Y C and Ho K C, Org Lett. ,2005, 7(10), 1899-1902; DOI:10.1021/o1050417f

39. Hagberg D P, Yum J H, Lee H, De Angelis F, Marinado T, Karlsson K M, HumphryBaker R, Sun L, Hagfeldt A, Grätzel M and Nazeeruddin M K, J Am Chem Soc., 2008, 130(19), 6259-6266; DOI:10.1021/ja800066y

40. Ma X, Hua J, Wu W, Jin Y, Meng F, Zhan W and Tian H, Tetrahedron, 2008, 64(2), 345-350; DOI:10.1016/j.tet.2007.10.094

41. Hagberg D P, Marinado T, Karlsson K M, Nonomura K, Qin P, Boschloo G, Brinck, T, Hagfeldt A and Sun L, J Org Chem., 2007, 72(25), 9550-9556; DOI:10.1021/jo701592x

42. Zhang G, Bala H, Cheng Y, Shi D, Lv X, Yu Q and Wang P, Chem Commun., 2009, 16, 2198-2200; DOI:10.1039/B822325D

43. Liang M, Xu W, Cai F, Chen P, Peng B, Chen J and Li Z, J Phys Chem C, 2007, 111(11), 4465-4472; DOI:10.1021/jp067930a

44. Hwang S, Lee J H, Park C, Lee H, Kim C, Park C, Lee M H, Lee W, Park J, Kim K, Park N G and Kim C, Chem Commun., 2007, 46, 4887-4889; DOI:10.1039/B709859F

45. Ci Z, Yu X, Bao M, Wang C and Ma T, Dyes Pigments, 2013, 96(3), 619-625; DOI:10.1016/j.dyepig.2012.11.004

46. Duan T, Fan K, Fu Y, Zhong C, Chen X, Peng T and Qin J, Dyes Pigments, 2012, 94(1), 28-33; DOI:10.1016/j.dyepig.2011.11.008

47. Dev P, Agrawal S and English N J, J Chem Phys., 2012, 136(22), 224301-224311; DOI:10.1063/1.4725540

48. Lange A W, Rohrdanz M A and Herbert J M, J Phys Chem B, 2008, 112(20), 63046308; DOI: 10.1021/jp802058k 
49. Rohrdanz M A and Herbert J M, J Chem Phys., 2008, 129, 034107 DOI:10.1063/1.2954017

50. Toulouse J, Colonna F and Savin A, J Chem Phys., 2005, 122(1), DOI:10.1063/1.1824896

51. Livshits E and Baer R, Phys Chem Chem Phys., 2007, 9, 2932-2941; DOI:10.1039/B617919C

52. Becke A D, J Chem Phys., 1993, 98, 5648-5652; DOI:10.1063/1.464913

53. Lee C, Yang W and Parr R G, Phys Rev B, 1988, 37(2), 785-789; DOI:10.1103/PhysRevB.37.785

54. Stephens P J, Devlin F J, Chabalowski C F and Frisch M, J Phys Chem., 1994, 98, 11623-11627; DOI:10.1021/j100096a001

55. Amovilli C, Barone V, Cammi R, Cancès E, Cossi M, Mennucci B, Pomelli C S and Tomasi J, Adv Quant Chem., 1998, 32, 227-261; DOI:10.1016/S00653276(08)60416-5

56. Tomasi J, Mennucci B and Cammi R, Chem Rev., 2005, 105(8), 2999-3094; DOI:10.1021/cr9904009

57. Frisch M J, Trucks G W, Schlegel H B, Scuseria G E, Robb M A, Cheeseman J R, Scalmani G, Barone V, Mennucci B, Petersson G A, Nakatsuji H, Caricato M, Li X, Hratchian H P, Izmaylov A F, Bloino J, Zheng G, Sonnenberg J L, Hada M, Ehara M, Toyota K, Fukuda R, Hasegawa J, Ishida M, Nakajima T, Honda Y, Kitao O, Nakai H, Vreven T, Montgomery J A, Jr, Peralta J E, Ogliaro F, Bearpark M, Heyd J J, Brothers E, Kudin K N, Staroverov V N, Kobayashi R, Normand J, Raghavachari K, Rendell A, Burant J C, Iyengar S S, Tomasi J, Cossi M, Rega N, Millam J M, Klene M, Knox J E, Cross J B, Bakken V, Adamo C, Jaramillo J, Gomperts R, Stratmann R E, Yazyev O, Austin A J, Cammi R, Pomelli C, Ochterski J W, Martin R L, Morokuma K, Zakrzewski V G, Voth G A, Salvador P, Dannenberg J J, Dapprich S, Daniels A D, Farkas Ö, Foresman J B, Ortiz J V, Cioslowski J and Fox D J, Gaussian, Inc., Wallingford CT, 2009.

58. Balanay M P and Kim D H, Phys Chem Chem Phys., 2008, 10, 5121-5127; DOI:10.1039/B806097E

59. De Angelis F, Fantacci S and Selloni A, Nanotechnology, 2008, 19(82), 424002, DOI:10.1088/0957-4484/19/42/424002

60. Ito S, Zakeeruddin S M, Humphry-Baker R, Liska P, Charvet R, Comte P, Nazeeruddin Md K, Pechy P, Takata M, Miura H, Uchida S and Grätzel M, $A d v$ Mater., 2006, 18(9), 1202-1205; DOI:10.1002/adma.200502540

61. Albert A, Heterocyclic Chemistry: an Introduction:London, 1968, Chapter 3.

62. Nalwa H S, Handbook of Advanced Electronic and Photonic Materials and Devices: San Diego CA, 2001, Chapter 2.

63. Asbury J B, Wang Y Q, Hao E, Ghosh H and Lian T, Res Chem Intermed., 2001, 27(4-5), 393-406; DOI:10.1163/156856701104202255

64. Katoh R, Furube A, Yoshihara T, Hara K, Fujihashi G, Takano S, Murata S, Arakawa H, Tachiya M, J Phys Chem B, 2004, 108, 4818-4822; DOI:10.1021/jp031260g.

65. Hagfeldt A and Grätzel M, Chem Rev., 1995, 95(1), 49-68; DOI:10.1021/cr00033a003 